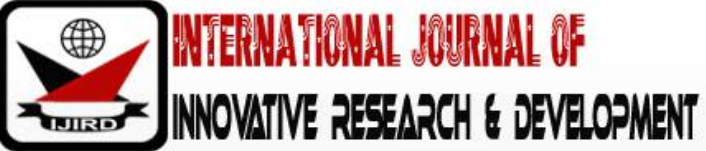

ISSN 2278-0211 (Online)

\section{Incidence, Risk Factor and Outcome of Neonatal Sepsis: A Retrospective Study among Neonates Admitted into General Hospital, Igbokoda, Ondo State, Nigeria}

Olajide, Adetunmise Oluseyi
Lecturer, Department of Nursing Sciences,
Ladoke Akintola University of Technology, Oyo State, Nigeria
Sowunmi, Christianah Olanrewaju
Associate Professor, Department of School of Nursing,
Babcock University, Ilisan-Remo, Ogun State, Nigeria
Arowojolu, Daniel
Nursing officer, Department of Nursing
General Hospital, Igbokoda, Ondo State, Nigeria
Ojo, Ajibola
Chief Nursing Officer, Department of Nursing
Ogunmodede, Eunice
Assistants Director, Department of Nursing
Ladoke Akintola University teaching Hospital, Ogbomoso, Oyo State, Nigeria
Ajibade, Bayo Lawal
Professor, Department of Nursing Sciences
Ladoke Akintola University of Technology, Oyo State, Nigeria

\begin{abstract}
Background: Globally, neonatal sepsis still remains the major cause of morbidity and mortality in neonates within 28days of life or younger, in spite of recent advances in the health care units. Higher percentage of under-five mortality occurs globally during the first week of newborns life which are related to neonatal and maternal risk factors.

Objectives: The objective of this study is to assess the incidence of neonatal sepsis and its risk factors among neonates admitted into General Hospital, Igbokoda. Retrospectively between the year January, 2016 and December, 2019.

Method: The research design used for study was cross sectional, retrospective and non-experimental design. The study was conducted at General Hospital, Igbokoda.The sample size was obtained from the record department based on the number of case files of the neonates admitted into General Hospital, Igbokoda from January 2016 - December 2019 that were retrieved using a purposive sampling technique while a structured check list with reliability index of 0.789 was used as the tool of data collection from Case files of neonates with the diagnosis of neonatal sepsis

Result: The findings revealed that the overall incidence rate of neonatal sepsis was 22.2 per 1000 livebirths among the total 120 neonates used in this study in which. The maternal factors identified to cause neonatal sepsis include maternal age 88 (73.3\%), parity 77 (64.2\%), digital examination 68 (56.7\%), level of education, place of delivery, PROM, and occupation. The study also revealed that neonatal factors causing neonatal sepsis are, neonatal age 115 (95.8\%), sex of the neonate, birth asphyxia, pgar score at birth 36 (30\%). The outcome of neonatal sepsis revealed that 49 (40.8\%) were discharged home without complication, 31 (25.8\%) were discharged home with complications, 36 (30.0\%) were referred and 4 (3.3\%) were recorded dead.

Conclusion: Based on the above outcome, it is recommended that more attention should be given to newborn care especially in their first week of life. Health education should be given to pregnant women within the vulnerable age during antenatal and post - natal visits. More attention should be given to the primipara women during labor and health care providers should ensure that digital vaginal examination is done when it is strictly needed.
\end{abstract}

Keywords: Incidence, neonatal sepsis, neonates. Retrospective study

\section{Introduction}

The first 28th days of life accounts for the most vulnerable period in life. This period accounts for 50-70\% of infant mortality and $39 \%$ of under 5 deaths and $40 \%$ of preventable child death in the USA and in Nigeria; 241,000 
newborns die from prevented and treatable causes every year giving a neonatal mortality rate of 40/1,000 live births. (Ekwochi, Ndu, Nwokoye, Ezenwosu, Amadi \& Osuorah, 2014). Studies carried out by WHO (2005), reported that over $70 \%$ of deaths in children under age five occur within the first year of life and $40 \%$ occur within the first month. Neonatal infections are frequent and important cause of morbidity and mortality in the neonatal period in which as many as $2 \%$ of fetuses are infected in utero, and up to $10 \%$ of infants have infections in the first month of life. Sepsis is the commonest cause of neonatal mortality and is responsible for $30-50 \%$ of total neonatal death each year in developing countries (Shallini \& Malik, 2010).

Neonatal sepsis is the leading cause of neonatal morbidity and mortality, particularly in the developing countries and it occurs as a result of systemic inflammatory response syndrome in the presence of or as a result of suspected or proven infection in neonate which could be bacterial, viral, fungal, or rickettsia in origin (Destaalem, Hattu \& Khsu, 2015). Bacterial organism causing neonatal sepsis may differ among countries, however, in most developing countries, gramnegative bacteria remain the major source of infection and these bacterial organisms have developed increased drug resistance to commonly used antibiotics, making its management a challenge for both the public and private health sectors (Destaalem et al, 2015). Neonatal sepsis continues to be a global burden in spite of great advances in antimicrobial therapy, neonatal support measure and early detection of risk factors which is due to high susceptibility of the newborn to infections, attributable to impaired immune defense system especially in the preterm, (West \& Tabansi, 2014) and other primary pathogens causing neonatal sepsis include Listeria Monocytogenes, Enterococcus, and other Gram-negative bacilli such as H. influenza, Klebseiella pneumonia, (Minyahil, Molla, Jimma, Gobezie, Gurmuand \& Hunduma, 2014).

Neonatal sepsis is one of the major health problems globally. Neonatal sepsis ranks the third as a leading cause of infant mortality worldwide, every year an estimated 30 million newborns acquire infection and 1-2 million of these die. About forty percent of under-five deaths occur in the neonatal period resulting in 2.9 million newborn deaths each year and the highest mortality rate for newborn are found in the poorest and low income countries and these deaths are attributed to infections acquired by the baby during labor and delivery or after birth in which Nigeria accounts for the highest number of neonatal death in Africa and third in the world after India and China, with neonatal sepsis responsible for about $30 \%$ to $50 \%$ of deaths and the mortality rates from neonatal sepsis have ranged from $26.7 \%$ in Abakaliki, to 32.2\% in Sagamu and 33.3\% in Ile-Ife, over the last two decades (Adediwura, David, Iyabode, Shittu \& Olusola, 2017).

Neonatal sepsis occurs during the first 28 days of life and is estimated to cause $26 \%$ of all neonatal death worldwide. (Asia, Herman, Avelina, Adella \& Joyce, 2016). Every year about 2.9 million neonates die as a result of neonatal sepsis worldwide and most of these occur in low resource settings (Violet, Jamili \& Charles, 2018). The incidence of neonatal sepsis varies from 6 to 9 cases per 1,000 live births, but higher among low-birth weight neonates and the World Health Organization estimated that there are approximately five million neonatal deaths per year of which $98 \%$ occur in developing countries (Destaalem et al, 2014). It is estimated that $20 \%$ of all neonates will develop sepsis and $1 \%$ of them will die as sepsis related causes (Shobowale, Ogunsola, Oduyebo \& Ezeaka, 2016). The incidence of neonatal sepsis in developing countries is much higher than that in developed countries. Globally, neonatal sepsis is the leading cause of neonatal morbidity and mortality accounting for $15 \%$ during the neonatal period next to preterm birth complications $24 \%$ (UNICEF, 2014). Neonatal sepsis shares the burden of health care problem in the world causing approximately 1.4 million neonatal deaths annually (Shane \& Stoll, 2014).

Several factors have been found to put neonate at risk of acquiring sepsis and these factors span from in-utero, peri-partum and post-partum factors, including newborn factors and the home and community where the baby is raised and the magnitude of the factors may vary from place to place and so it is also important to know the community specific factors (Violet et al, 2018)

Moreover, the estimation of the incidence of neonatal sepsis is important in planning for the health care system's response to sick neonates in terms of personnel, commodities and inpatient care (Violet et al, 2018). Despite advancements of neonatal sepsis diagnosis and management, neonatal sepsis still remains the leading cause of neonatal admission and mortality in neonatal intensive care unit, especially in developing country (Satar \& Ozlu, 2012) and out of the three leading cause of neonatal mortality, sepsis is the third and share about $13 \%$ of neonatal mortality (Danzhen et al., 2015). Due to all the aforementioned points, it is therefore necessary to assess the incidence of neonatal sepsis among the neonates admitted into General Hospital, Igbokoda.

\subsection{Objective of the Study}

\subsubsection{General Objectives}

The general objective of this study is to evaluate the retrospective incidence of neonatal sepsis and its risk factors among neonates admitted into General Hospital, Igbokoda between January 2016 and December, 2019

\subsubsection{Specific Objectives}

- To determine the total number of neonatal sepsis admitted into General Hospital, Igbokoda between January 2016 to December 2019.

- To determine the incidence of neonatal sepsis admitted into General Hospital, Igbokoda between January 2016 to December 2019.

- To assess maternal factors responsible for neonatal sepsis admitted into General Hospital, Igbokoda between January 2016 to December 2019.

- To assess neonatal factors responsible for neonatal sepsis admitted into General Hospital, Igbokoda between January 2016 to December 2019. 
- To assess the outcome of neonatal sepsis admitted into General Hospital, Igbokoda between January 2016 to December 2019.

\subsection{Research Questions}

- What is the total number of neonatal sepsis cases admitted into General Hospital, Igbokoda between January 2016 to December 2019?

- What is the incidence of neonatal sepsis among neonates admitted into General Hospital, Igbokoda between January 2016 to December 2019?

- What are the maternal factors responsible for neonatal sepsis admitted into General Hospital, Igbokoda between January 2016 to December 2019?

- What are the neonatal factors responsible for neonatal sepsis admitted into General Hospital, Igbokoda between January 2016 to December 2019?

- What is the outcome of neonatal sepsis cases admitted into General Hospital, Igbokoda between January 2016 to December 2019?

\subsection{Significance of the Study}

The result of this study may help the policy makers formulate policy and program manager's plan for appropriate intervention and training based on the result for health professionals, which helps them to improve their knowledge regarding to neonatal sepsis.

The result of this study may provide relevant information on the incidence of neonatal sepsis. The findings may enable the researcher to known the risk factors associated with the incidence of neonatal sepsis among the hospitalized neonates

It will be helpful for the hospitals to improve their health care management for the neonate based on the result with the intention of the neonate to have standard and better quality care.

The findings will enable nurses and other stake holders to develop health promotion programs to enhance prompt report of suspected cases of neonatal sepsis for early diagnosis and treatment as to reduce the rate of neonatal morbidity and mortality.

The study makes an important addition to the existing literatures to aid for further researchers who are interested in conducting researches on the issue under consideration at different time and places.

\section{Method}

\subsection{Research Design}

Cross sectional, retrospective and non-experimental study design was used for this research, which means that the samples was taken from the study population and the information was obtained at the same time at a particular point in time.

\subsection{Research Setting} this study.

The study was conducted at General Hospital, Igbokoda where the research data was collected for the purpose of

General Hospital, Igbokoda is a secondary health care setting situated at the heart of Ilaje local government in Ondo South at 152, Omonira street, Igbokoda. It was founded in the year 1973. General Hospital, Igbokoda comprises of different departments such as Out Patient Department, 10 bedded Male ward, 10 bedded Female Wards, 10 bedded Maternity ward, 10 bedded Children wards, Antenatal Clinic, Pharmacy, Laboratory, Records, Store and Account departments and some other offices. The hospital has 54 medical staffs and 21 non-medical staffs. It serves as one of the referral centers for all comprehensive health centers and mobile clinics in the coastal areas of Ondo State especially within Ilaje Local government

\subsection{Research Study Population}

Population refers to the entire group of people that the researcher wished to investigate. This study was conducted among the neonates admitted into General Hospital, Igbokoda between January 2016 - December 2019 which gives sum total of 5,400 neonates admitted within the period of the study year as provided by the record department. The researcher selected neonates age range between 0day - 8weeks of life who were diagnosed of neonatal sepsis.

\subsection{Sample Size Determination}

The sample size was obtained from the record department based on the number of case files of the neonates admitted into General Hospital, Igbokoda from January 2016 - December 2019 that were retrieved.

$\mathrm{N}=$ Summation of neonatal case files from year January 2016 - December 2019

$2016=17$

$2017=32$

$2018=33$

$2019=38$

Total $=(2016+2017+2018+2019)$

Total $=17+32+33+38$ 
Total Cases $=120$

Therefore, Sample size is 120

\subsection{Sampling Technique}

A purposive technique was used to obtain data from the case files of the neonates admitted in the hospital neonatal ward between January 2016 - December 2019.

\subsection{Instrumentation}

A structured check list was used as the tool to collect the data based on the review of the relevant literature of incidence of neonatal sepsis from the case files of neonates admitted between January 2016 - December 2019.

\subsection{Pilot Study}

19 samples of the checklist were used to collect data from the study population at State Specialist Hospital, Okitipupa, Ondo State to test the validity and reliability of the instrument for the purpose of generalizability.

\subsection{Psychometric Properties of Instrument}

\subsubsection{Validity of Instrument}

The check list was constructed in accordance with the literature review on and the stated objectives of the study. The check list was given to supervisor for scrutiny, clarification of items. The corrected checklist was then approved for distribution.

\subsubsection{Reliability of Instrument}

The reliability of the instrument was tested using Cronbach Alpha and yielded reliability index of 0.789 depicting good reliability.

\subsection{Data Collection Method}

The ethical committee of General Hospital, Igbokoda was met and approval was obtained for data collection, informed consent was also taken from the ethical committee. Two research assistants were recruited and trained by the investigators. The neonatal medical record identification numbers were sent to the medical record department for the retrieval of the medical files.

\subsection{Method of Data Analysis}

The data collected was analyzed statistically through Statistical Product and Services Solution (SPSS Version 20) and IBM. Findings were represented using appropriate tables, percentage and chart. Interpretations was made

\subsection{Ethical Consideration}

An approval was obtained from the ethical committee for the approval of the collection of data

\section{Results}

\begin{tabular}{|c|c|c|}
\hline & Frequency & Percentage \\
\hline \multicolumn{3}{|c|}{ Age } \\
\hline 0 - 7 days & 57 & 47.5 \\
\hline 1 week - 4 weeks & 50 & 41.7 \\
\hline 1 month - 5 months & 12 & 10.0 \\
\hline 6 months - 12 months & 1 & .8 \\
\hline Total & 120 & 100.0 \\
\hline \multicolumn{3}{|c|}{ Sex } \\
\hline Male & 61 & 50.8 \\
\hline Female & 59 & 49.2 \\
\hline Total & 120 & 100.0 \\
\hline \multicolumn{3}{|c|}{ Religion } \\
\hline Christianity & 61 & 50.8 \\
\hline Islam & 59 & the 49.2 \\
\hline Total & 120 & 100.0 \\
\hline \multicolumn{3}{|c|}{ Weight } \\
\hline $1.5 \mathrm{~kg}-2.0 \mathrm{~kg}$ & 25 & 20.8 \\
\hline $2.0 \mathrm{~kg}-2.5 \mathrm{~kg}$ & 25 & 20.8 \\
\hline $2.6 \mathrm{~kg}-3.0 \mathrm{~kg}$ & 17 & 14.2 \\
\hline $3.1 \mathrm{~kg}-3.5 \mathrm{~kg}$ & 32 & 26.7 \\
\hline $3 . \mathrm{kg}-4.5 \mathrm{~kg}$ & 21 & 17.5 \\
\hline Total & 120 & 100.0 \\
\hline
\end{tabular}

Table 1: Socio Demographic Characteristics 
The socio-demographic characteristics of the neonates show that $47.5 \%$ of the respondents are between the ages of 0 to 7 days, $41.7 \%$ between 1 week to 4 weeks, $10 \%$ between 1 month to 5 months, and $0.8 \%$ between 6 months to 12 months. The sex of the respondents shows that $50.8 \%$ of the neonates are male while $49.2 \%$ are female.

Their religion is either male or female, with $50.8 \%$ being male and $49.2 \%$ being female. $50.8 \%$ are Christians and $49.2 \%$ are Muslims. And their weight ranges from $1.5 \mathrm{~kg}-2.0 \mathrm{~kg}$ (20.8\%), $20.8 \%$ also from $2.0 \mathrm{~kg}$ to $2.5 \mathrm{~kg}$, $14.2 \%$ from $2.6 \mathrm{~kg}$ to $3.0 \mathrm{~kg}, 26.7 \%$ which is the majority between $3.1 \mathrm{~kg}$ to $3.5 \mathrm{~kg}$ and $17.5 \%$ between $3 \mathrm{~kg}$ to $4.5 \mathrm{~kg}$.

- $\quad$ Research Question 1: What is the total number of neonatal sepsis cases admitted into General Hospital, Igbokoda between January 2016 to December 2019?

\begin{tabular}{|c|c|c|}
\hline & Frequency & Percentage \\
\hline 2016 & 17 & 14.2 \\
\hline 2017 & 32 & 26.7 \\
\hline 2018 & 33 & 27.5 \\
\hline 2019 & 38 & 31.7 \\
\hline Total & 120 & 100.0 \\
\hline
\end{tabular}

Table 2: Showing the Number of Neonatal Cases in Each Year

Out of the total 120 cases of neonatal sepsis, 17 which is the lowest occurred in 2016, 32 in 2017,33 cases in 2018 and 38 cases in 2019. There are more cases in recent times than the previous times

- Question 2: What is the incidence of neonatal sepsis admitted into general hospital between 2016 and 2019.

The incidence rate of neonatal sepsis per 1000 live birth can therefore be calculated as;

Total Number of reported cases $=120$

Total number of neonatal admission $=5400$

Total number of reported cases of neonatal sepsis during the study period / Total number of neonatal admission $\times 1000$

$(17+32+33+38) / 5,400 \times 1000$

$120 / 5,400 \times 1000=22.22$

Therefore, it can be inferred that the incidence of neonatal sepsis during the study period is relatively high at 22.2 per 1000 live births.

- Research Question 3: What are the maternal factors responsible for neonatal sepsis admitted into General Hospital, Igbokoda between January 2016 to December 2019?

\begin{tabular}{|c|c|c|c|c|c|c|c|}
\hline & & 2016 & 2017 & 2018 & 2019 & Total & RII \\
\hline \multirow[t]{2}{*}{ Maternal Age } & Yes & $12(13.6 \%)$ & $24(27.3 \%)$ & $22(25.0 \%)$ & $30(34.1 \%)$ & \multirow[t]{2}{*}{88} & \multirow[t]{2}{*}{1} \\
\hline & No & $5(15.6 \%)$ & $8(25.0 \%)$ & $11(34.4 \%)$ & $8(25.0 \%)$ & & \\
\hline \multirow[t]{2}{*}{ Occupation } & Yes & $7 \quad(18.4 \%)$ & $9(23.7 \%)$ & $13(34.2 \%)$ & $9(23.7 \%)$ & \multirow[t]{2}{*}{38} & \multirow[t]{2}{*}{10} \\
\hline & No & $10(12.3 \%)$ & $23(28.4 \%)$ & $19(23.5 \%)$ & $29(35.8 \%)$ & & \\
\hline \multirow[t]{2}{*}{ Level of Education } & Yes & $10(16.4 \%)$ & $15(24.6 \%)$ & $15(24.6 \%)$ & $21(34.4 \%)$ & \multirow[t]{2}{*}{61} & \multirow[t]{2}{*}{4} \\
\hline & No & $7 \quad(11.9 \%)$ & $17(28.8 \%)$ & $18(30.5 \%)$ & $17(28.8 \%)$ & & \\
\hline \multirow[t]{2}{*}{ Parity } & Yes & $11(14.3 \%)$ & $20(26.0 \%)$ & $21(27.3 \%)$ & $25(32.5 \%)$ & \multirow[t]{2}{*}{77} & \multirow[t]{2}{*}{2} \\
\hline & No & $6(14.0 \%)$ & $12(27.9 \%)$ & $12(27.9)$ & $13(30.2 \%)$ & & \\
\hline \multirow[t]{2}{*}{ Place of delivery } & Yes & $12(20.7 \%)$ & $13(22.4 \%)$ & $12(20.7 \%)$ & $21(36.2 \%)$ & \multirow[t]{2}{*}{58} & \multirow[t]{2}{*}{6} \\
\hline & No & $5(8.1 \%)$ & $19(30.6 \%)$ & $21(33.9 \%)$ & $17(27.4 \%)$ & & \\
\hline \multirow{2}{*}{$\begin{array}{l}\text { Prolonged Premature } \\
\text { rupture of membrane }\end{array}$} & Yes & $3(5.2 \%)$ & $19(32.8 \%)$ & $19(32.8 \%)$ & $17(29.3 \%)$ & \multirow[t]{2}{*}{58} & \multirow[t]{2}{*}{6} \\
\hline & No & $14(22.6 \%)$ & $13(21.0 \%)$ & $14(22.6 \%)$ & $21(33.9 \%)$ & & \\
\hline \multirow{2}{*}{$\begin{array}{c}\text { Digital Vaginal } \\
\text { examination }\end{array}$} & Yes & $9(13.2 \%)$ & $18(26.5 \%)$ & $20(29.4 \%)$ & $21(30.9 \%)$ & \multirow[t]{2}{*}{68} & \multirow[t]{2}{*}{3} \\
\hline & No & $8(15.4 \%)$ & $14(26.9 \%)$ & $13(25.0 \%)$ & $17(32.7 \%)$ & & \\
\hline \multirow[t]{2}{*}{ Maternal febrile illness } & Yes & $11(18.0 \%)$ & $15(24.6 \%)$ & $15(24.6 \%)$ & $20(32.8 \%)$ & \multirow[t]{2}{*}{61} & \multirow[t]{2}{*}{4} \\
\hline & No & $6(10.2 \%)$ & $17(28.8 \%)$ & $18(30.5 \%)$ & $18(30.5 \%)$ & & \\
\hline \multirow[t]{2}{*}{ History of UTI/STI } & Yes & $5(8.6 \%)$ & $17(29.3 \%)$ & $17(29.3 \%)$ & $19(32.8 \%)$ & \multirow[t]{2}{*}{58} & \multirow[t]{2}{*}{6} \\
\hline & No & $12(19.4 \%)$ & $15(24.2 \%)$ & $16(25.8 \%)$ & $19(30.6 \%)$ & & \\
\hline \multirow[t]{2}{*}{ Others } & Yes & $1(10.0 \%)$ & $0 \quad(0.0 \%)$ & $4(40.0 \%)$ & $5(50.0 \%)$ & \multirow[t]{2}{*}{10} & \\
\hline & No & $16(14.5 \%)$ & $32(29.1 \%)$ & $29(26.4 \%)$ & $33(30.0 \%)$ & & \\
\hline
\end{tabular}

Table 3: Showing Maternal Factors Responsible for Neonatal Sepsis Admitted into General Hospital, Igbokoda between January 2016 to December 2019

The table above shows the maternal factors that cause neonatal sepsis. The factors range from maternal age to History of UTI/STI and other factors. The highest maternal factor that causes neonatal sepsis is maternal age. There were 88 cases in total due to maternal age. Least cases occurred due to mother's occupation (38 cases) and others (10). In 2016, highest number of cases due to maternal causes is due to maternal age (12), and the lowest is due to prolonged premature rupture ( 3 cases) and other reasons (1 case). Likewise, in 2017, highest occurrence was due to maternal age (24 cases) and lowest due to mother's occupation (9 cases) with no case due to other reasons. In 2018, maternal age (22 cases) remains the highest cause and the least by place of delivery (12 cases) and 4 cases due to other reasons. In 2019 , maternal 
age with 30 neonatal sepsis cases remain the highest cause of maternal mortality while the least cause is by mother's occupation ( 9 cases) and other reasons with 5 cases.

The Relative Importance Index (RII) showed maternal age as the major cause of neonatal sepsis due to maternal mortality, followed by parity, and mother's occupation as the least cause.

- Research Question 4: What are the neonatal factors responsible for neonatal sepsis admitted into General Hospital, Igbokoda between January 2016 to December 2019?

\begin{tabular}{|c|c|c|c|c|c|c|c|}
\hline & & $\mathbf{2 0 1 6}$ & $\mathbf{2 0 1 7}$ & $\mathbf{2 0 1 8}$ & $\mathbf{2 0 1 9}$ & $\begin{array}{c}\text { Total } \\
\text { cases }\end{array}$ & RII \\
\hline Age of the child & Yes & $17(14.8 \%)$ & $31(27.0 \%)$ & $29(25.2 \%)$ & $38(33.0 \%)$ & 115 & 1 \\
& No & $0(0.0 \%)$ & $1(20.0 \%)$ & $4(80.0 \%)$ & $0(0.0 \%)$ & & \\
\hline Sex & Yes & $16(14.2 \%)$ & $30(26.5 \%)$ & $31(27.4 \%)$ & $36(31.9 \%)$ & 113 & 2 \\
& No & $1(16.7 \%)$ & $1(16.7 \%)$ & $2(33.3 \%)$ & $2(33.3 \%)$ & & \\
\hline Birth Weight & Yes & $10(52.6 \%)$ & $2(10.5 \%)$ & $3(15.8 \%$ & $4(21.1 \%)$ & 19 & 5 \\
& No & $7(6.9 \%)$ & $30(29.7 \%)$ & $30(29.7 \%)$ & $34(33.7 \%)$ & & \\
\hline Agar Score & Yes & $3(8.3 \%)$ & $15(41.7 \%)$ & $6(16.7 \%)$ & $12(33.3 \%)$ & 36 & 4 \\
& No & $14(16.7 \%)$ & $17(20.2 \%)$ & $27(32.1 \%)$ & $26(31.0 \%)$ & & \\
\hline Gestational Age & Yes & $6(9.4 \%)$ & $13(20.3 \%)$ & $20(31.2 \%)$ & $25(39.1 \%)$ & 64 & 3 \\
& No & $11(19.6 \%)$ & $19(33.9 \%)$ & $13(23.2 \%)$ & $13(23.2 \%)$ & & \\
\hline Birth Asphyxia & Yes & $4(21.1 \%)$ & $7(36.8 \%)$ & $6(31.6 \%)$ & $2(10.5 \%)$ & 19 & 5 \\
& No & $13(12.9 \%)$ & $25(24.8 \%)$ & $27(26.7 \%)$ & $36(35.6 \%)$ & & \\
\hline Others & Yes & $0(0.0 \%)$ & $0(0.0 \%)$ & $1(50.0 \%)$ & $1(50.0 \%)$ & 2 & \\
& No & $17(14.4 \%)$ & $32(27.1 \%)$ & $32(27.1 \%)$ & $37(31.4 \%)$ & & \\
\hline
\end{tabular}

Table 4: Showing Neonatal Factors Responsible for Neonatal Sepsis Admitted into General Hospital, Igbokoda between January 2016 to December 2019

The table shows the neonatal factors responsible for neonatal sepsis. Out of the total cases in 2016, 17 cases which was the highest was due to age of the child and the least occurrence was due to Agar score ( 3 cases). In 2017, the neonatal factor that caused neonatal sepsis the most was due to age of child (31 cases), and birth weight is the least score with 2 cases. In 2018, age of the child serves remained the main cause (29 cases) while birth weight remains the least score ( 3 cases). In 2019, age of the child retained being the highest cause of neonatal sepsis (38 cases) and the least cause is birth asphyxia ( 2 cases).

In total, age of the child has been the main neonatal factor that caused neonatal sepsis, followed closely by the sex of the baby, and then gestational age which ranked as the third cause. The least causes are birth weight and birth asphyxia.

- Research Question 5: What is the outcome of neonatal sepsis cases admitted into General Hospital, Igbokoda between January 2016 to December 2019?

\begin{tabular}{|c|c|c|c|c|c|}
\hline & \multicolumn{3}{|c|}{ Outcome of the Sepsis } & \multirow{2}{*}{ Total } \\
\cline { 2 - 5 } & $\begin{array}{c}\text { Discharged without } \\
\text { complication }\end{array}$ & $\begin{array}{c}\text { Discharge with } \\
\text { complication }\end{array}$ & Referred & Death & \\
\hline 2016 & $9(52.9 \%)$ & $3(17.6 \%)$ & $3(17.6 \%)$ & $2(11.8 \%)$ & $17(100 \%)$ \\
\hline 2017 & $12(37.5 \%)$ & $8(25.0 \%)$ & $10(31.2 \%)$ & $2(6.2 \%)$ & $32(100 \%)$ \\
\hline 2018 & $12(36.4 \%)$ & $7(21.2 \%)$ & $14(42.4 \%)$ & $0(0.0 \%)$ & $33(100.0 \%)$ \\
\hline 2019 & $16(42.1 \%)$ & $13(34.2 \%)$ & $9(23.7 \%)$ & $0(0.0 \%)$ & $38(100.0 \%)$ \\
\hline Total & $49(40.8 \%)$ & $31(25.8 \%)$ & $36(30.0 \%)$ & $4(3.3 \%)$ & $120(100.0 \%)$ \\
\hline
\end{tabular}

Table 5: Showing the Outcome of Neonatal Sepsis Cases Admitted into General

Hospital, Igbokoda between January 2016 to December 2019

Of all the 17 cases that occurred in 2016, 52.9\% of the cases resulted into discharge with no complication, $17.6 \%$ each resulted to either discharge with complications or referred while $11.8 \%$ resulted to death. In 2017 where there were 32 cases, $37.5 \%$ resulted to discharge with no complications, $25 \%$ resulted to discharge with complications, $31.2 \%$ of them were referred and $6.2 \%$ resulted to death. In 2018, of all the 33 cases, $36.4 \%$ resulted to discharge with no complications, $21.2 \%$ resulted to discharge with complication, $42.4 \%$ resulted to them being referred, while none led to death. In 2019 , where there were 38 cases, none led to death, $42.1 \%$ led to discharge with no complications, $34.2 \%$ led to discharge with complications and $23.7 \%$ were referred.

\section{Discussion}

It can be inferred from table 2 that during the study period, a total of 120 cases of neonatal sepsis were reported from the total of 5,400 live births recorded from January 2016 to December 2019 as provided by the record department of the hospital in which the study revealed the overall incidence rate of neonatal sepsis was 22.2 per 1000 livebirths and the incidence increases from 2016 to 2019 as supported by Nubwa et al. (2014) also supported that the incidence of neonatal sepsis was at 18.3/1000 lives births and that of GBS sepsis at 0.06/1000 live births is significant which warrants active measures to reduce and Adediwura et al (2017) also supported that the overall incidence of neonatal sepsis was 2.76 per 
1000 livebirths and it. The study showed that 120 (100\%) of neonates recruited into this study are diagnosed of neonatal sepsis, majority, $57(47.5 \%)$ of which are between age 0 to 7 days and 61 (50.8\%) were male while 59 (49.2\%) were female as shown in table 4.1 and supported by Perera, Weerasekera \& Weerasinghe, (2018) which showed that out of the total 306 neonates (age in between 0-28 days) recruited for a study, 249 (82.4\%) were age less than or equal to 7 days with early onset of neonatal sepsis.

Table 4.1 Majority of the neonates are below 1 month of age as supported by Ekwochi, Ndu,Nwokoye, Ezenwosu, Amadi \& Osuorah, (2014) that the first 28th days of life accounts for the most vulnerable period in life. There are slightly higher numbers of male cases than female cases as established by Shruti, Myron, Vasudeva, Leslie, Simon \& Sreekumaran, (2019) that male neonates are more sensitive to adverse perinatal and postnatal environmental conditions, and are more likely to be born preterm and with a low birth weight, both of which increase the risk of neonatal sepsis.

Table 3 shows that of out of all the maternal factors that cause neonatal sepsis, maternal age which account for 88 of total cases serves as the major maternal factors that caused neonatal mortality followed by parity 77 , digital vaginal examination 68, level of education 62, place of delivery, prolonged premature rupture of membrane 58 , and occupation is 38 as Bua, Mukanga and Nabiwemba (2014) showed that there was a high proportion of laboratory confirmed newborn sepsis cases among mothers in 20-29 years' age group, with only 5years education and farming occupation. Moreover, this research finding was also supported by Vijai et al (2014) which revealed that out of 120 neonates more than half were born to the mother of 20-25 years, one-fourth each to mothers of $<20$ and $>25$ years of age and the difference in the mortality rate is not significant in which nearly three-fourth of the babies were born to illiterate mothers and the mortality was significantly more (57.5\%) compared with those born to educated mothers (18.2\%). Perera et al; 2018 also supported the finding in their study that $118(73 \%)$ mothers had 3 or more vaginal examinations which is the commonest risk factors of neonatal sepsis as well as Adediwura et al. (2017) who opined that 85 neonates, 28 (32.9\%) were in-born babies, while $57(67.1 \%)$ were out-born babies at home or at traditional birth centers, $21(36.8 \%)$ in private nursing homes and 25 (43.9\%) in hospitals or clinics

According to table 4, findings revealed that the age of the neonate accounts for 115 neonates of the total cases as the major cause of neonatal sepsis and this goes in tandem with findings of Bua et al. (2014) that a higher proportion of confirmed sepsis cases were among sick newborns in first week of life, born before term and delivered at the traditional birth attendant.

Table 4.8 also shows that out of the neonatal factors causing neonatal sepsis, the sex of the neonates accounts for 113 of the total cases as supported by Prarthana, (2018) that revealed male infants are 2-6 times more at risk of neonatal septicemia than female and that out of 130 neonates with clinical suspicion of septicemia studied, 53.8\% were males and $46.2 \%$ were females. Study showed that female neonates were less likely to develop neonatal sepsis than male (Peter et al; 2019) but on a contrary, Ginenus, Tsega \& Tesfa, (2019) in their study revealed that out of a total of 306 study population, $173(56.54 \%)$ neonates were females as compared to male neonates which indicate female predominance in developing neonatal sepsis.

Table 5 shows that of all the total 120 cases, 4 cases of neonatal sepsis lead to death; 2 cases in 2016 and also 2 cases in 2017 which was also reported by Adediwura (2017) that neonatal sepsis is responsible for about 30\% to 50\% of deaths and the mortality rates from neonatal sepsis have ranged from $26.7 \%$ in Abakaliki, to $32.2 \%$ in Sagamu and $33.3 \%$ in Ile-Ife, over the last two decades.

Moreover, table 5 also shows that of all the total 120 (100\%) cases, 49 (40.8\%) were discharged home without complication, 31 (25.8\%) were discharged home with complications, 36 (30.0\%) were referred and 4 (3.3\%) were recorded dead as supported by Bua eta al., (2014) that out of 150 neonates recruited into the study on admission, about 89 $(84 \%)$ were discharged home without complication after completing the treatment, 40 (37\%) were discharged home with complications while 9 (14\%) were dead. On a contrary, Ginenus, Tsega \& Tesfa, (2019) revealed that regarding the clinical outcome of the hospitalized neonates, out of 145 neonates admitted, $82(60.19 \%)$ were recovered from their condition with improvement of which a total of 12 (3.92\%) mortality was recorded. However, the outcome of neonates with sepsis is strongly related to their appropriate diagnosis and treatment which could be challenging as 12 (3.92\%) of the neonates died on hospitalization.

\section{Limitation of the study}

The study made use of secondary data which is patient case files / hospital records of neonates that has been admitted into the hospital in previous years. The records were adapted to the study and no new questions could be asked to explore new things, thus the study is limited. Also, there was no qualitative records to probe further on some of the factors that needed further exploration.

\section{Conclusion}

From this study, it can be recommended that government, health-facilitators, non-governmental organizations should:

- Provide more facilities and equipment to treat neonatal sepsis and reduce its mortality incidence as it is a major contributor to neonatal mortality.

- Serious attention/focus should be provided to male babies as they are more susceptible to neonatal sepsis.

- Women who give birth between the ages 20-29 years of age should be given lectures/seminars on neonatal sepsis and best means of preventing this as they are a major age group of interest as regards neonatal sepsis.

- Babies in their first month, especially first week of birth should be given proper care and examined regularly. 


\section{References}

i. Adediwura O.A, David A.O, Iyabode O.D, Olufunke B.S, \& Olushola A.A (2017) Neonatal Sepsis in a Nigerian Tertiary Hospital: Clinical Features, Clinical Outcome, etiology and antibiotic susceptibility pattern, Southern African Journal of Infectious Disease, 32:4, 127-131, DOI:10.1080/23120053.2017.1335962

ii. Asia J., Herman L.W, Avelina. S, Adella. S\&Joyce. P (2016): Prevalence and factors associated with neonatal sepsis among neonates attending Temeke and Mwananymala Hospital in Dar es Salaam, Tanzania. Tanzania Journal of Health Research Vol 18 (4), October 2016.

iii. Bua .J, Mukanga .D, Lwanga .M \& Nabiwemba .E (2015), Risk Factors and Practices Contributing to Newborn Sepsis in a Rural District of Eastern Uganda, August 2013: a sectional study. Article number: 339(2015). Published on: 09 August 2015.

iv. Dastaalem .G, Haftu .B, \& Kahsu .G (2016): Risk Factors for Neonatal Sepsis in Public Hospitals of Mekelle City, North Ethiopia, 2015: Unmatched case Control Study, PLoS ONE 11(5):e0154798.doi:10.1371/journal.pone.0154798.

v. Ekwochi .U, Ndu I.K, Nwokoye I.C, Ezenwosu O.U, Amadi O.F \& Osuorah D.I, 2014, Pattern of Morbidity and Mortality of Newborns Admitted into the Sick and Special Care Baby Unit of Enugu State University Teaching Hospital, Enugu State. Nigerian Journal of Clinical Practice; 2014. Vol 17. Issu 3. Pg:346-351.

vi. Ginenus .F, Tsega .A \& Tesfa .T (2019), Clinical Treatment Outcomes of Neonatal Sepsis in Neonatal Intensive Care Unit of Wollega University Teaching and Referral Hospital, Nekemte Town, Western Ethiopia. D0I: 10.4172/21610665.1000353

vii. Minyahil A.W, Molla B.G, Jimma L.L, Gobezie T.T, Gurmu .T \& Hunduma .D (2014) Assessment of the incidence of Neonatal epsis, its Risk Factors, antimicrobials Use and Clinical Outcomes in Bishoftu General Hospital, Neonatal Intensive Care Unit, Debrezeit- Ethiopia, Pediatric and Therapeutic Research Article ISSN: 2161-0665.

viii. Nubwa .M, Kenneth .I, Pui-Ying I.T, \& Stephen .O (2014), Aetiology of neonatal sepsis in Nigeria, and relevance of Group B Stretococcus: A systematic review. https://journals.plos.org

ix. Perera K.S, Weerasekera M \& Weerasinghe D.T (2018), Risk Factors for early neonatal sepsis in the term baby. Sri Lanka Journal of Child Health, 2018; 47(1):44-49

X. Prarthana M.S (2018), Maternal Factor as Risk for Neonatal Sepsis, IOSR Journal of Dental and Medical Sciences. EISSN: 2279-0853, p-ISSN: 2279-0861. Volume 17, Issue 3 Ver. 14 March, (2018), PP 18-23. www.iosrjournals.org

xi. Satar, M. \& Ozlu, F., (2012). Neonatal sepsis: A Continuing Disease Burden. Turkey Journal of Pediatrics. Vol 54, Issue 5

xii. Shobowale E.0, Ogunsola F.T, Oduyebo 0.0, \& Ezeaka V.I (2016): Aetiology and Risk factors for Neonatal Sepsis at the Lagos, Nigeria, S African Journal Child Health 2016;10(3):147-150. DOI:10.7196/SAJCH. 216.v1013.965

xiii. Shruti .M, Myson. A, Vasudeva. G, Lesile. E, Simon. L\&Sreekumaran. N, 2019. Risk Factors of neonatal sepsis in Indian: A systematic review and meta-analysis

xiv. Shallini, T \&Malik, G.K. (2010). Neonatal Sepsis: Past, Present and Future; a review article. Internet Journal of Medical Update; vol:5, Issue 2

xv. Vijai. A, Babu. B\& Syamala S.D (2014) Neonatal Sepsis: A risk approach Vol 3(4) pg 254-258.

xvi. Violet O.K, Jamiie. M \& Charles.K (2018) Burden and factors associated with clinical neonatal sepsis in urban Uganda: A community cohot study. Published: 13 November 2018.

xvii. West \& Tabansi (2014) Prevalence of neonatal septicemia in the University of Port Harcourt Teaching Hospital, Nigeria. Nijer J Pead 2014; 41 (1):33-37. 